\title{
Osseodensification Drilling vs. Standard Protocol of Implant Site Preparation: An In Vitro Study on Polyurethane Foam Sheets
}

\author{
Luca Comuzzi ${ }^{1,+}$, Margherita Tumedei ${ }^{2, *,+}$, , Adriano Piattelli ${ }^{2,3,4}$ and Giovanna Iezzi ${ }^{2}$ \\ 1 Private Practice, San Vendemiano-Conegliano, 31020 Treviso, Italy; luca.comuzzi@gmail.com \\ 2 Department of Medical, Oral and Biotechnological Sciences, University “G. D'Annunzio" of Chieti-Pescara, \\ 66100 Chieti, Italy; apiattelli@unich.it (A.P.); gio.iezzi@unich.it (G.I.) \\ 3 Biomaterials Engineering, Catholic University of San Antonio de Murcia (UCAM), 30001 Murcia, Spain \\ 4 Fondazione Villaserena per la Ricerca, Città Sant'Angelo, 65121 Pescara, Italy \\ * Correspondence: margytumedei@yahoo.it; Tel.: +39-0871-355-4083 \\ + These two authors had an equal contribution to the study.
}

Received: 3 May 2020; Accepted: 27 May 2020; Published: 29 May 2020

\begin{abstract}
Background: The aim of the present in vitro investigation was to evaluate, on polyurethane sheets, two different drilling techniques for dental implant positioning using osteocondensing burs compared to a standard type protocol. (2) Methods: Three different implant designs (Implacil De Bortoli UN III $4 \times 10$ mm, Restore RBM 4 (HEX) × 10 mm; Implacil De Bortoli UN II $4 \times 10 \mathrm{~mm}$ ) were evaluated (test implant (osteocondensing drills) and control implant (standard drills)). The insertion torque (IT), the removal torque (RT) and the resonance frequency analysis (RFA) values of test and control implants inserted in different size and different density polyurethane foam models were compared for 120 experimental sites. Accordingly, 120 experimental holes were produced in different PCF polyurethane foams: 60 sites were produced in 10 PCF sheets and 60 sites in 10 PCF sheets with an additional $1 \mathrm{~mm}$ layer of 30 PCF. (3) Results: The IT, removal torque and RFA values were significantly higher for both of the evaluated implants, in the sites prepared with the osteocondenser drills when compared to sites prepared with standard drills $(p<0.05)$. The UNII and UN III showed significantly higher stability compared to the HEX implant; these differences increased drastically in the 10 PCF Polyurethane Block with the additional $1 \mathrm{~mm}$ cortical layer $(p<0.05)$. (4) Conclusions: The outcome of this investigation suggested a possible clinical application of osteocondensing burs in case of reduced bone quality and quantity in the posterior maxilla.
\end{abstract}

Keywords: osseodensification; polyurethane model; primary stability; implant

\section{Introduction}

The implant site osteotomy represents a key surgical phase to obtain primary stability during the screw positioning in clinical practice [1-3]. In the literature, the primary stability has been demonstrated as a necessary condition to obtain the osseointegration of the dental implant, in order to support the masticatory loading $[2,4,5]$.

This feature is conditioned by several factors related to the surgical technique, bone quantity and density, macro and microgeometry of the dental implant [2,6-8].

According to the Misch classification (1988), the decreased bone density and the lack of bone cortical, such as D4 bone type, could influence the obtaining of primary stability during the implant positioning [9]. Several techniques had been proposed to increase primary stability in vivo in maxillary posterior region such as: under-preparation drilling protocols, manual condensation osteotomy, piezoelectric devices [10-13]. 
The most used materials for implant drills is steel cooled with saline irrigation, but also zirconia drills have been proposed to decrease the temperature generated during implant osteotomy [14,15].

The Osseodensification drilling protocol is a new generation technique able to increase the primary stability in poor density bone. This procedure had been proposed to increase the quality of the osteotomy, densification of the bone site, indirect sinus augmentation and bone expansion [16,17]. Lahens et al. reported in poor density bone that implants positioned by osseodensification protocol showed a higher level of stability compared to standard subtractive drilling techniques at 12 weeks. No significant differences were reported about the osseointegration quality [18].

The polyurethane sheet model represents an in vitro study design for a dental implant able to standardize the biomechanical evaluation in order to generate a reduction in the experimental variables, with a high level of translational power for clinical applications [19-21]. As reported by Comuzzi et al., this study model permits to investigate the primary stability of a dental implant concerning the insertion torque (IT), removal strength torque (RT) and implant stability quotient measurements (ISQ) [16-19].

The aim of the present study was to evaluate on polyurethane foam sheets, the primary stability of dental implants positioned by Osseodensification drilling technique compared to the standard drilling protocol.

\section{Results}

The normality test null hypothesis could not be rejected $(p$-value $>0.05)$ and a normal distribution of the study data was present.

No significant differences were found in the values of the Test A and Test B implants between the standard and osseodensification protocol (Figure 1, Table 1). In both these implants, the insertion torque was quite low in the 10 pcf blocks, with a significant increase in the primary stability in $10 \mathrm{pcf}$ blocks with a $1 \mathrm{~mm} 30$ Pcf cortical layer, that resulted in a very good stability of the implants $(p<0.01)$ (Figure 1, Table 1).

\section{INSERTION TORQUE}

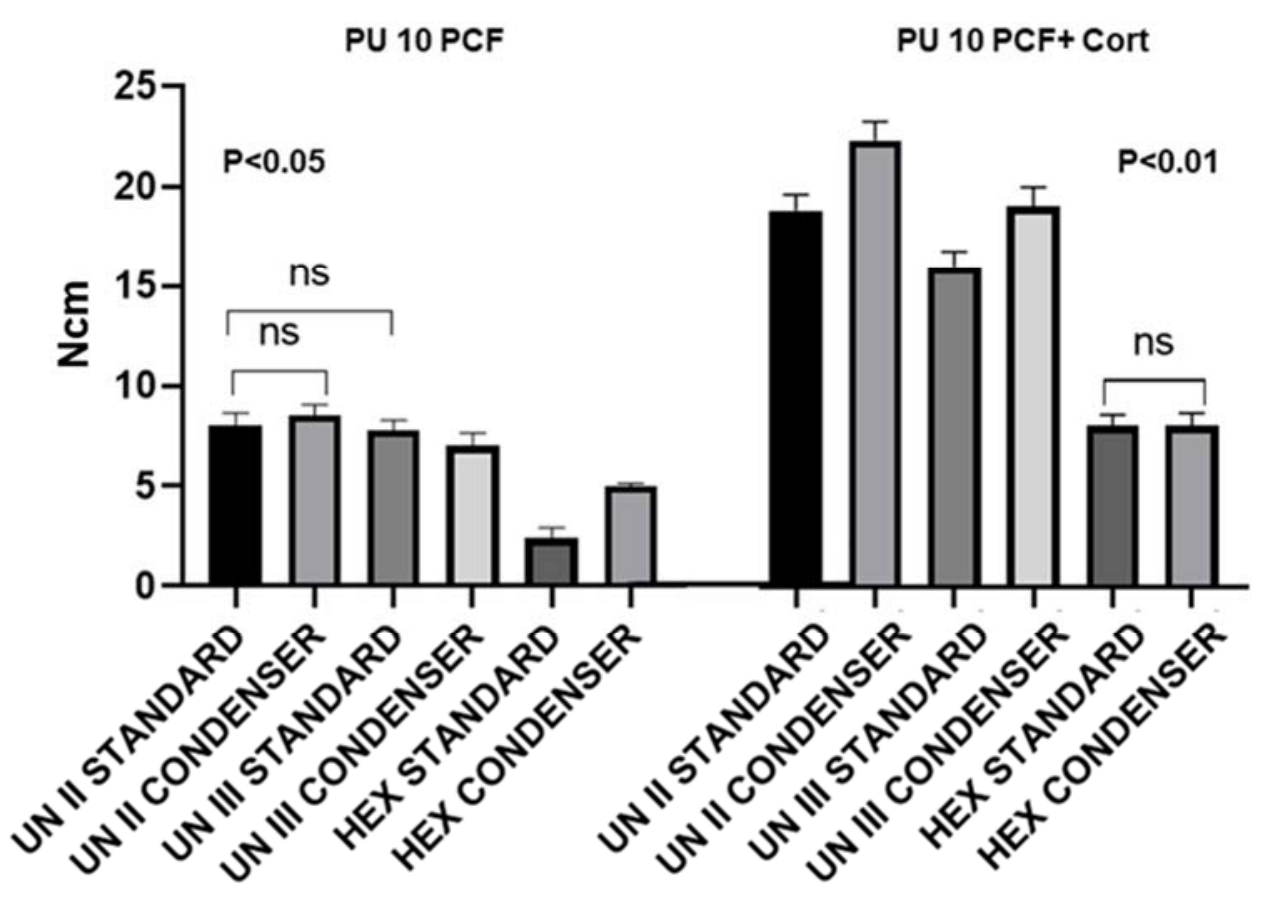

Figure 1. Insertion torque of the UN II, UNIII and HEX implant. n.s. not significant. 
Table 1. Summary of insertion torque (IT), removal strength torque (RT) and implant stability quotient (ISQ) means and standard deviation of the experimental conditions.

\begin{tabular}{|c|c|c|c|c|c|c|c|c|c|c|c|c|c|}
\hline & & \multicolumn{6}{|c|}{10 PCF } & \multicolumn{6}{|c|}{10 PCF/Cort } \\
\hline & & $\begin{array}{l}\text { UN II } \\
\text { Stand }\end{array}$ & $\begin{array}{l}\text { UN II } \\
\text { Cond }\end{array}$ & $\begin{array}{l}\text { UN III } \\
\text { Stand }\end{array}$ & $\begin{array}{l}\text { UN III } \\
\text { Cond }\end{array}$ & $\begin{array}{l}\text { HEX } \\
\text { Stand }\end{array}$ & $\begin{array}{l}\text { HEX } \\
\text { Cond }\end{array}$ & $\begin{array}{l}\text { UN II } \\
\text { Stand }\end{array}$ & $\begin{array}{l}\text { UN II } \\
\text { Cond }\end{array}$ & $\begin{array}{l}\text { UN III } \\
\text { Stand }\end{array}$ & $\begin{array}{l}\text { UN III } \\
\text { Cond }\end{array}$ & $\begin{array}{c}\text { HEX } \\
\text { Stand }\end{array}$ & $\begin{array}{l}\text { HEX } \\
\text { Cond }\end{array}$ \\
\hline \multirow{2}{*}{ IT } & Mean & 8.00 & 8.53 & 7.78 & 6.99 & 2.41 & 5.01 & 18.8 & 22.3 & 15.96 & 18.99 & 8.02 & 8.02 \\
\hline & SD & 0.62 & 0.52 & 0.48 & 0.62 & 0.50 & 0.12 & 0.79 & 0.95 & 0.77 & 0.97 & 0.53 & 0.62 \\
\hline \multirow{2}{*}{ RT } & Mean & 4.5 & 6.4 & 5.4 & 4.8 & 2.01 & 4.26 & 16 & 19.9 & 12.7 & 12 & 5.4 & 5.4 \\
\hline & SD & 0.52 & 0.51 & 0.51 & 0.34 & 0.62 & 0.79 & 0.66 & 0.73 & 1.25 & 0.82 & 0.66 & 0.66 \\
\hline \multirow{2}{*}{ ISQ } & Mean & 44.85 & 44.85 & 43.8 & 39.75 & 31 & 31.55 & 52 & 57 & 49.85 & 45.9 & 32.45 & 34.1 \\
\hline & SD & 1.06 & 0.85 & 1.67 & 1.32 & 0.78 & 1.86 & 1.37 & 1.05 & 1.67 & 0.94 & 3.34 & 2.21 \\
\hline
\end{tabular}


A significant difference was present between the conical shape implants (Tests A and B) and the cilindrical implant, where the osseodensification drilling protocol showed a higher level of insertion torque levels $(p<0.01)$ (Figure 1 , Table 1$)$.

The removal values for both of these test implants were slightly lower than the insertion torque values in all experimental conditions (Figure 2). High ISQ values were found in both test implants (40-60) (Figure 3).

\section{REMOVAL TORQUE}

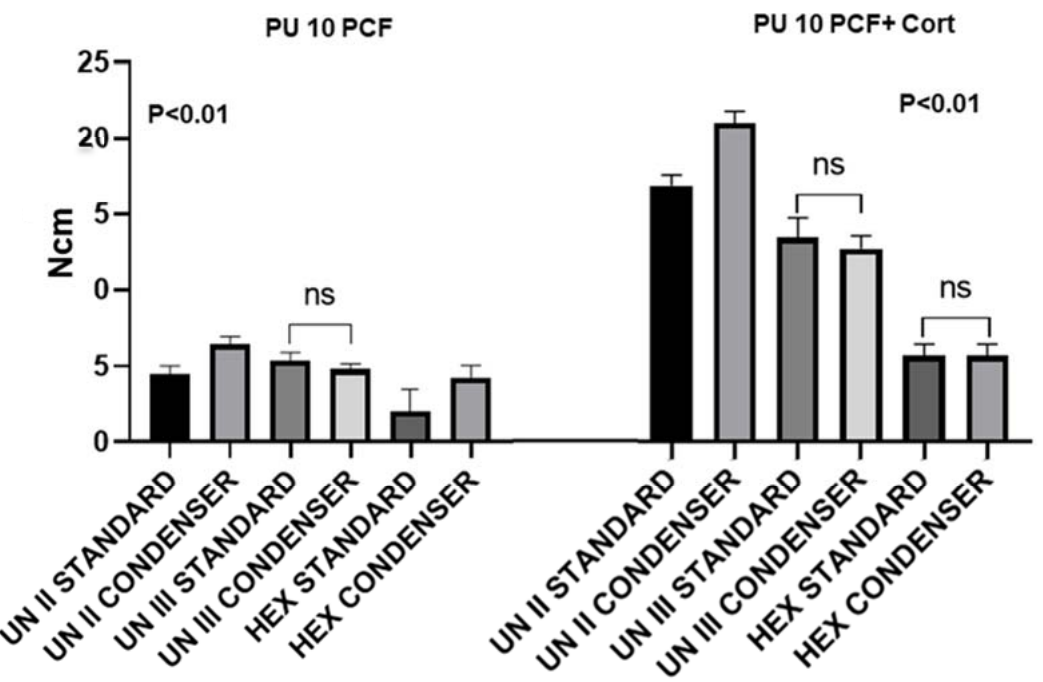

Figure 2. Removal torque of the UN II, UNIII and HEX implant. n.s. not significant.

ISQ

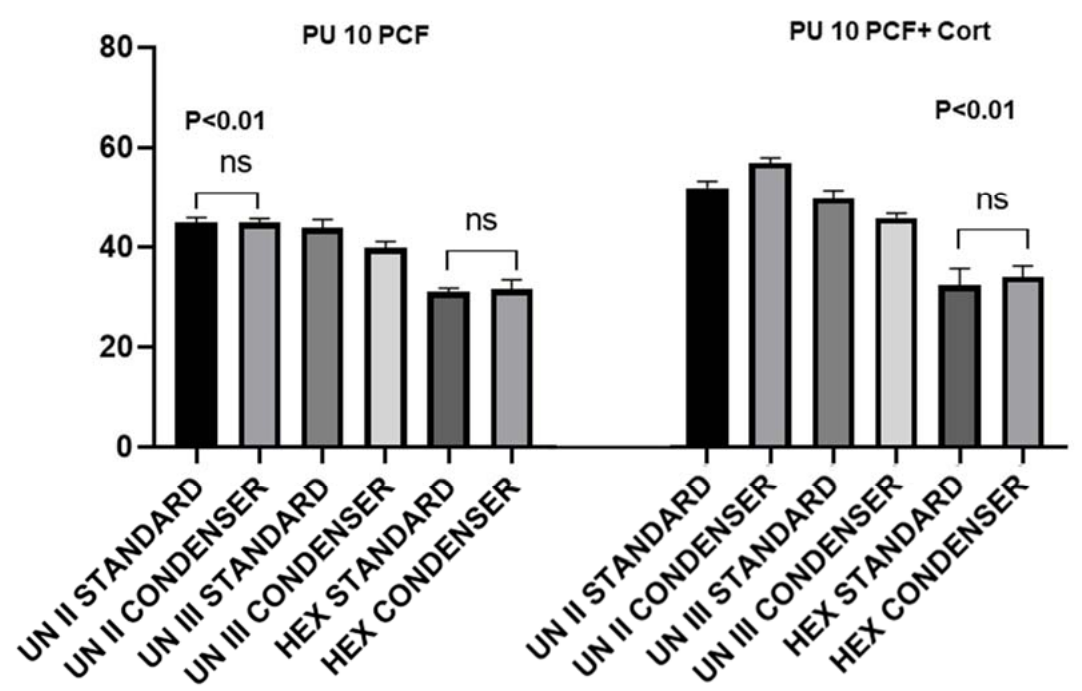

Figure 3. Resonance frequency analysis (RFA) of the UN II, UNIII and HEX implant. n.s. not significant.

Control implants, on the other hand, presented very low insertion torque values $(20-40 \mathrm{Ncm})$ in both polyurethane densities (Figure 3). 


\section{Discussion}

The posterior region of the jaws is often associated with a decrease in bone quality causing the loss of teeth [22-24]. Implant positioning for oral rehabilitations of these regions could often represents a clinical challenge to obtain screw implant stability $[10,25,26]$.

The first outcome of the present study was that the conical shape implant produced a significant increase in insertion stability strength, associated with higher values of ISQ if compared to the cylindrical screws.

As reported in literature studies, the macro-geometry of the dental implant is a key factor that produces a direct influence on Insertion Torque, Removal and Micromovement measurement $[27,28]$.

Moreover, the associated conical microgeometry macrostructure seems to produce a positive effect on implant screw stability during the positioning with a higher stability if compared to the cylindrical implants.

The main characteristics of the study design model could represent an important variable, in terms of the bone density and cortical component of the experimental site and a translational value of the study effectiveness [19].

In fact, Almutairi et al. reported no significant differences in implant stability and insertion torque in an ex vivo model of a Cow femur bone [29].

Different drilling preparation techniques of implant bed preparation have been described in the literature $[25,26]$. Scarano et al. reported no statistical differences among fifty patients who experienced crestal bone resorption when comparing ultrasonic vs. drilling implant site preparation methods [30].

Regarding the bone heat generation, several factors such as drill geometry, drilling depth, profile sharpness, drilling speed, pressure, drilling technique, and use or not of irrigation could influence the temperature increase in the apical portion of the drill [14,26,31,32].

Lahens et al. in sheep ilium reported a significant higher stability with implant positioned with Osseodensification protocol [18].

The purpose of this new concept of the implant osteotomy protocol is to induce a controlled expansion of the implant site preparation with a clockwise rotation of the drill $[17,18]$.

The osseodensification procedure is a technique able to produce a deposit of crusts of compact bone of $0.1-0.3 \mathrm{~mm}$ if compared to an undersized drilling technique that is able to produce a plastic deformation of the implant site osteotomy walls [6].

Moreover, the osseodensification technique is able to provide a less traumatic surgery, a reduction of surgery times and pain, a positive effect on maturation of the bone tissue and implant healing if compared to different alternative surgery expansion techniques such as split osteotomy [30,33].

In the present study, the effect of Osseodensification drilling protocol seems to produce no significant effectiveness on primary stability with discordant effects under in vitro standardized conditions on a polyurethane block.

The polyurethane sheet simulation provides a highly standardized design model for dental implant and drilling preparation techniques. In fact, several bone substrates have been proposed for in vitro implant studies such as bovine ribs, sheep mandible, pig tibiae and human cadaveric bones; however, local anatomical and density variability, environmental and sample temperature and humidity, as well as biological sample conservation represent potential limitations and determinant factors $[5,27,33-41]$.

In fact, Trisi et al. reported, in a sheep study, a significant increase in the bone volume percentage $(\mathrm{bV} \%)$ in the test site compared to the standard osteotomy protocol [42].

In the present investigation osseodensification drilling technique showed a significant increase in the insertion torque in very low-density bone with a $1 \mathrm{~mm}$ cortical layer, but no detectable differences were present in the absence of a cortical layer.

Chávarri-Prado et al. reported in a polyurethane study that the presence of the cortical layer represents a positive influence for the implant primary stability [43]. 
In order to facilitate a clinical translational application, the presence of the cortical component of the substrate seems to be a key determinant for the micro-mechanical engagement of the dental implant surface and the surrounding bone.

\section{Materials and Methods}

\subsection{Implants}

Two different Cone Morse connections and a conical shape implant were tested: UNII (Test A) and UNIII (Test B) (Implacil De Bortoli, Sao Paulo, Brasil). The size of Cone Morse implants were $4 \mathrm{~mm}$ diameter and $10 \mathrm{~mm}$ length.

The Test A implant presented a narrow-thread shape, double thread pitch, and self-tapping apex [44]. The Test B macro design presented wider thread, no double thread pitch, a round, not self-tapping, apex with healing chambers between the cutting surface of the threads [44].

Moreover, a cylindrical screw-shaped implant was used as control implant (Restore, Keystone Dental, Burlington, MA, USA). The size of the control implant was $4.1 \mathrm{~mm}$ diameter and $10 \mathrm{~mm}$ length.

\subsection{Polyurethane Sheets Foam}

According to the previous study by Comuzzi et al. [19,44], two different types of solid rigid polyurethane $120 \mathrm{~mm} \times 170 \mathrm{~mm} \times 31 \mathrm{~mm}$ foam blocks (SawBones $\mathrm{H}$, Pacific Research Laboratories Inc., Vashon, WA, USA) were used for this study: the first one characterized by 10 pounds per cubic foot (pcf) with a $1 \mathrm{~mm}$ cortical of $30 \mathrm{pcf}$, and the second characterized by 10 pounds per cubic foot (pcf) without cortical.

\subsection{Experimental Design and Sample Size}

The Sample-size calculation was based on mean and standard deviation of a previous study [44], with an alpha error of 0.05 , an effect size of 0.75 , and power (1-beta) of 0.95 . The minimum number was 42 sites for each drilling protocol, for a total of 84 sites.

A total of 120 preparation sites were performed for the present investigation. Ten implants respectively for Test A and Test $B$ Implants for both of the drilling protocols and polyurethane densities (total 80 implants), and 10 control implants for each experimental condition (10 and 20 pcf) (total 40 implants).

\subsection{Osseodensification Drilling Protocol}

The osseodensification protocol was applied using the $2 \mathrm{~mm}$ drill, $3 \mathrm{~mm}$ drill and $3.5 \mathrm{~mm}$ drill (Figure 4). 


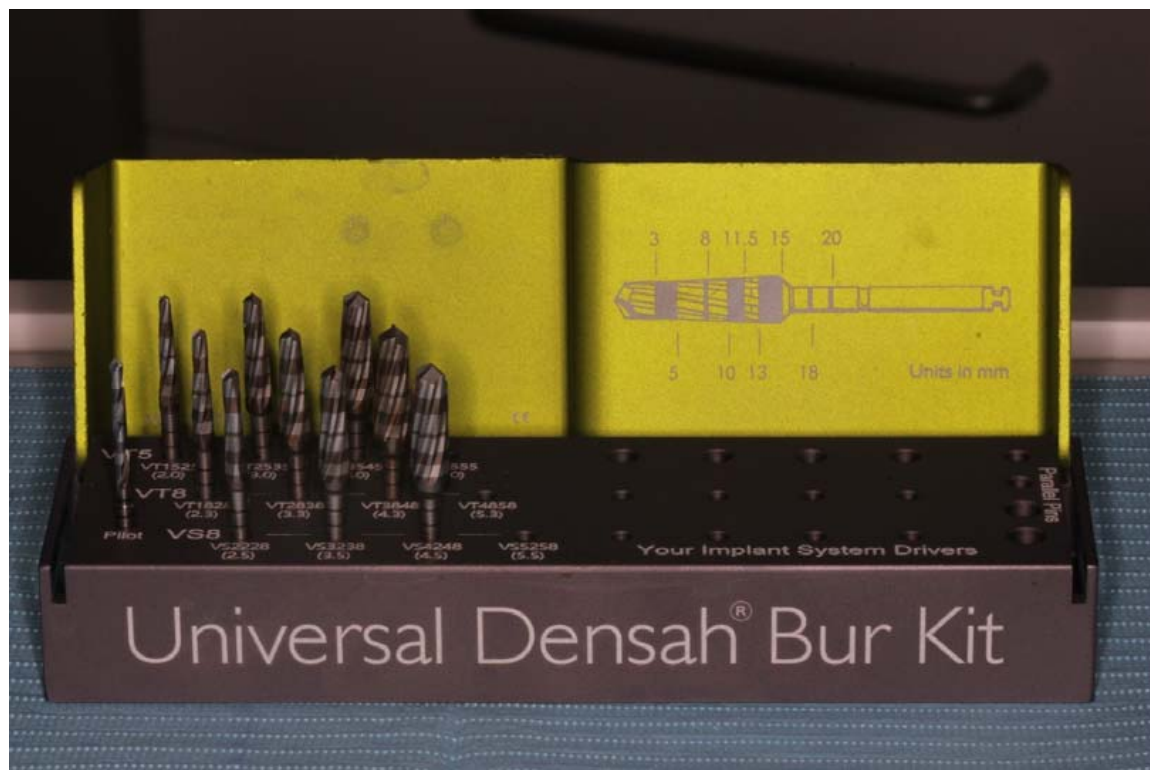

Figure 4. Osseodensification drilling kit used in the present study.

The experimental drills were all used in counter-clockwise rotation to provide a condensation effect at the level of the implant site. The standard drilling and the implant positioning were performed following the dental implant manufacturer's protocol (Figure 5).

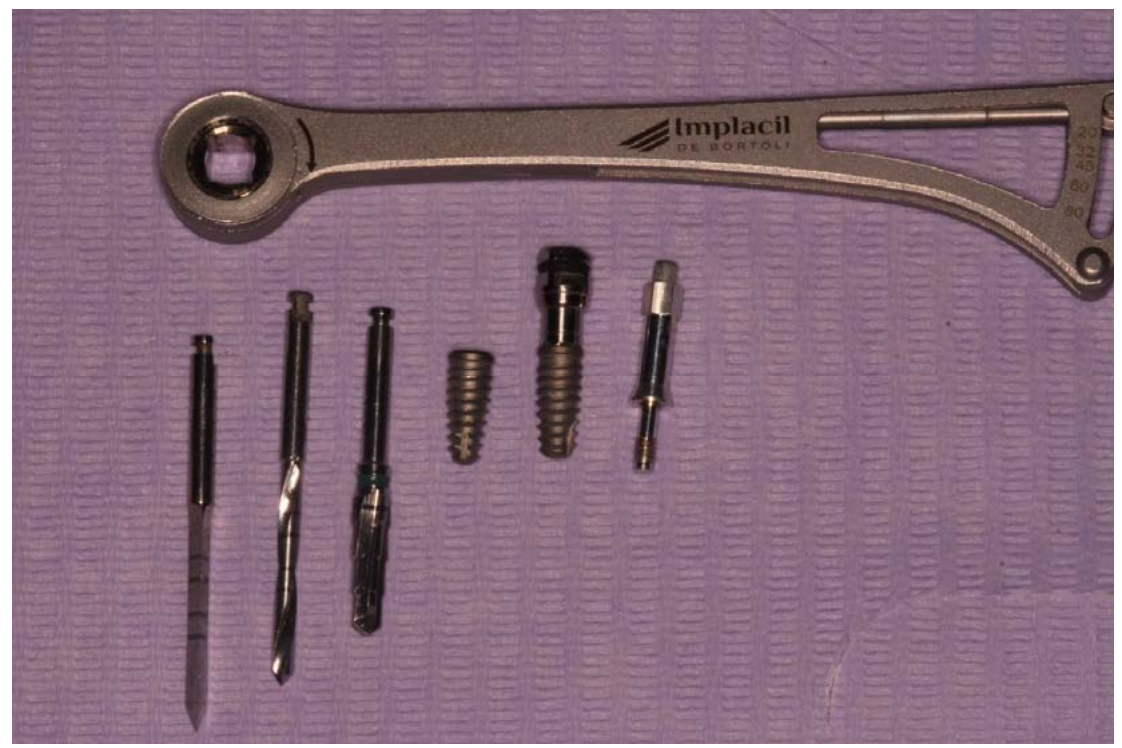

Figure 5. UNII and UNIII Cone Morse Implant. In detail the standard drilling sequence protocol. Lance, pilot $2.1 \mathrm{~mm}$ and final conical drill. A cylindrical final drill was used to position the control implant.

\subsection{Stability Measurement}

The insertion torque was measured by the dental implant surgical motor during the positioning of the screw. The Removal torque was recorded by a high precision electronic dynamometric torquemeter to evaluate the extraction resistance of the implant from the preparation site.

The implant stability quotient (RFA) method is carried out by an electromechanical measurement. An electrically and electronically controlled high sensitive device applied on implant screw. 
The implant stability quotient (ISQ) ranged from 0 to 100 and the range was divided into low (less than 60 ISQ), medium (60-70 ISQ), and high stability (more than 70 ISQ). For each specimen, the RFA measurement was repeated 2 times (Figure 6).

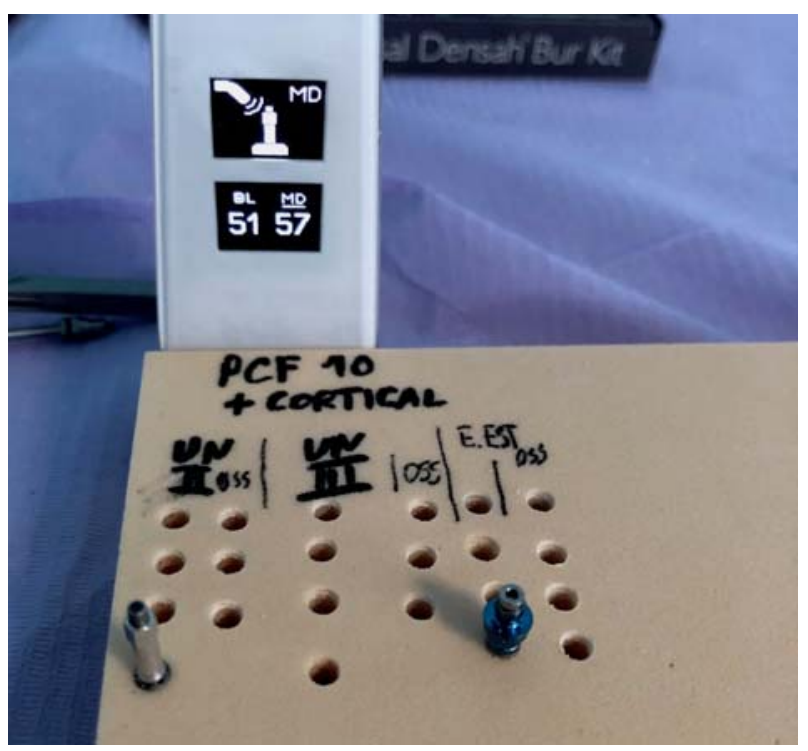

Figure 6. Implant positioned into the polyurethane block. ISQ measurement.

\subsection{Statistical Analysis}

The insertion torque, removal torque and ISQ means were statistically analysed by the Shapiro-Wilks test to evaluate the normal distribution of the study data, where the null hypothesis tested was that study data were normally distributed. The two-way ANOVA followed by the Tukey post-hoc test was performed to evaluate the inter-group comparisons. The descriptive statistics and statistical data evaluation were performed by the software package GraphPad 6.0 (Prism San Diego, CA, USA). The level of significance was set for $p<0.05$.

\section{Conclusions}

According to the evidences of the present investigation and the limits of in vitro polyurethane research, macro-geometry seems to produce the main important influence on the primary stability condition of poor density bone. The osseodensification drilling protocol seems to produce a positive influence for primary stability in poor density bone with a residual cortical component.

Author Contributions: Conceptualization: A.P. and G.I.; methodology: A.P., L.C. and G.I.; software: M.T.; validation: A.P. and G.I.; formal analysis: M.T. and A.P.; investigation: A.P.; resources: A.P. and G.I.; data curation: M.T. and L.C.; writing-original draft preparation: A.P. and M.T.; writing—review and editing: A.P. and M.T.; funding acquisition: A.P. All authors have read and agreed to the published version of the manuscript.

Funding: The manuscript authors declare no external funding for the present research investigation.

Acknowledgments: The authors declare no acknowledgments for this study.

Conflicts of Interest: The authors declare no conflict of interest.

\section{References}

1. Degidi, M.; Daprile, G.; Piattelli, A. Primary stability determination by means of insertion torque and RFA in a sample of 4135 implants. Clin. Implant Dent. Relat. Res. 2012, 14, 501-507. [CrossRef] [PubMed]

2. Javed, F.; Romanos, G.E. The role of primary stability for successful immediate loading of dental implants. A literature review. J. Dent. 2010, 38, 612-620. [CrossRef] [PubMed] 
3. Gehrke, S.A.; Tumedei, M.; Aramburú Júnior, J.; Treichel, T.L.E.; Kolerman, R.; Lepore, S.; Piattelli, A.; Iezzi, G. Histological and Histomorphometrical Evaluation of a New Implant Macrogeometry. A Sheep Study. Int. J. Environm. Res. Public Health 2020, 17, 3477. [CrossRef]

4. Tumedei, M.; Piattelli, A.; Degidi, M.; Mangano, C.; Iezzi, G. A Narrative Review of the Histological and Histomorphometrical Evaluation of the Peri-Implant Bone in Loaded and Unloaded Dental Implants. A 30-Year Experience (1988-2018). Int. J. Environ. Res. Public Health 2020, 17, 2088. [CrossRef] [PubMed]

5. Scarano, A.; Crocetta, E.; Quaranta, A.; Lorusso, F. Influence of the Thermal Treatment to Address a Better Osseointegration of Ti6A14V Dental Implants: Histological and Histomorphometrical Study in a Rabbit Model. Biomed. Res. Int. 2018, 2018, 2349698. [CrossRef]

6. Huwais, S.; Meyer, E.G. A Novel Osseous Densification Approach in Implant Osteotomy Preparation to Increase Biomechanical Primary Stability, Bone Mineral Density, and Bone-to-Implant Contact. Int. J. Oral Maxillofac. Implants 2017, 32, 27-36. [CrossRef] [PubMed]

7. Möhlhenrich, S.C.; Heussen, N.; Elvers, D.; Steiner, T.; Hölzle, F.; Modabber, A. Compensating for poor primary implant stability in different bone densities by varying implant geometry: A laboratory study. Int. J. Oral Maxillofac. Surg. 2015, 44, 1514-1520. [CrossRef] [PubMed]

8. Javed, F.; Almas, K.; Crespi, R.; Romanos, G.E. Implant surface morphology and primary stability: Is there a connection? Implant Dent. 2011, 20, 40-46. [CrossRef] [PubMed]

9. Misch, C.E.; Judy, K.W. Classification of partially edentulous arches for implant dentistry. Int. J. Oral Implantol. 1987, 4, 7-13. [PubMed]

10. Degidi, M.; Daprile, G.; Piattelli, A. Influence of underpreparation on primary stability of implants inserted in poor quality bone sites: An in vitro study. J. Oral Maxillofac. Surg. 2015, 73, 1084-1088. [CrossRef]

11. Degidi, M.; Perrotti, V.; Shibli, J.A.; Mortellaro, C.; Piattelli, A.; Iezzi, G. Evaluation of the peri-implant bone around parallel-walled dental implants with a condensing thread macrodesign and a self-tapping apex: A 10-year retrospective histological analysis. J. Craniofac. Surg. 2014, 25, 840-842. [CrossRef] [PubMed]

12. Alam, K.; Muhammad, R.; Shamsuzzoha, A.; AlYahmadi, A.; Ahmed, N. Quantitative analysis of force and torque in bone drilling. J. Eng. Res. [TJER] 2017, 14, 39-48. [CrossRef]

13. Zizzari, V.L.; Berardi, D.; Congedi, F.; Tumedei, M.; Cataldi, A.; Perfetti, G. Morphological Aspect and iNOS and Bax Expression Modification in Bone Tissue Around Dental Implants Positioned Using Piezoelectric Bone Surgery Versus Conventional Drill Technique. J. Craniofac. Surg. 2015, 26, 741-744. [CrossRef] [PubMed]

14. Scarano, A.; Lorusso, F.; Noumbissi, S. Infrared Thermographic Evaluation of Temperature Modifications Induced during Implant Site Preparation with Steel vs. Zirconia Implant Drill. J. Clin. Med. 2020, 9, 148. [CrossRef] [PubMed]

15. Scarano, A.; Petrini, M.; Mastrangelo, F.; Noumbissi, S.; Lorusso, F. The Effects of Liquid Disinfection and Heat Sterilization Processes on Implant Drill Roughness: Energy Dispersion X-ray Microanalysis and Infrared Thermography. J. Clin. Med. 2020, 9, 1019. [CrossRef] [PubMed]

16. Degidi, M.; Daprile, G.; Piattelli, A.; Iezzi, G. Development of a new implant primary stability parameter: Insertion torque revisited. Clin. Implant Dent. Relat. Res. 2013, 15, 637-644. [CrossRef]

17. Padhye, N.M.; Padhye, A.M.; Bhatavadekar, N.B. Osseodensification-A systematic review and qualitative analysis of published literature. J. Oral Biol. Craniofac. Res. 2020, 10, 375-380. [CrossRef]

18. Lahens, B.; Neiva, R.; Tovar, N.; Alifarag, A.M.; Jimbo, R.; Bonfante, E.A.; Bowers, M.M.; Cuppini, M.; Freitas, H.; Witek, L.; et al. Biomechanical and histologic basis of osseodensification drilling for endosteal implant placement in low density bone. An experimental study in sheep. J. Mech. Behav. Biomed. Mater. 2016, 63, 56-65. [CrossRef]

19. Comuzzi, L.; Iezzi, G.; Piattelli, A.; Tumedei, M. An In Vitro Evaluation, on Polyurethane Foam Sheets, of the Insertion Torque (IT) Values, Pull-Out Torque Values, and Resonance Frequency Analysis (RFA) of NanoShort Dental Implants. Polymers 2019, 11, 1020. [CrossRef]

20. Comuzzi, L.; Tumedei, M.; Piattelli, A.; Iezzi, G. Short vs. Standard Length Cone Morse Connection Implants: An In Vitro Pilot Study in Low Density Polyurethane Foam. Symmetry 2019, 11, 1349. [CrossRef]

21. Di Stefano, D.A.; Arosio, P.; Gastaldi, G.; Gherlone, E. The insertion torque-depth curve integral as a measure of implant primary stability: An in vitro study on polyurethane foam blocks. J. Prosthet Dent. 2018, 120, 706-714. [CrossRef]

22. Tumedei, M.; Savadori, P.; Del Fabbro, M. Synthetic Blocks for Bone Regeneration: A Systematic Review and Meta-Analysis. Int. J. Mol. Sci. 2019, 20, 4221. [CrossRef] 
23. Gehrke, S.A.; Mazón, P.; Del Fabbro, M.; Tumedei, M.; Aramburú Júnior, J.; Pérez-Díaz, L.; De Aza, P.N. Histological and Histomorphometric Analyses of Two Bovine Bone Blocks Implanted in Rabbit Calvaria. Symmetry 2019, 11, 641.

24. Araújo, M.G.; Silva, C.O.; Misawa, M.; Sukekava, F. Alveolar socket healing: What can we learn? Periodontol. 2000 2015, 68, 122-134. [CrossRef] [PubMed]

25. Scarano, A.; Piattelli, A.; Assenza, B.; Carinci, F.; Di Donato, L.; Romani, G.L.; Merla, A. Infrared thermographic evaluation of temperature modifications induced during implant site preparation with cylindrical versus conical drills. Clin. Implant Dent. Relat. Res. 2011, 13, 319-323. [CrossRef] [PubMed]

26. Scarano, A.; Carinci, F.; Lorusso, F.; Festa, F.; Bevilacqua, L.; Santos de Oliveira, P.; Maglione, M. Ultrasonic vs Drill Implant Site Preparation: Post-Operative Pain Measurement Through VAS, Swelling and Crestal Bone Remodeling: A Randomized Clinical Study. Materials (Basel) 2018, 11, 2516. [CrossRef] [PubMed]

27. Falco, A.; Berardini, M.; Trisi, P. Correlation between Implant Geometry, Implant Surface, Insertion Torque, and Primary Stability: In Vitro Biomechanical Analysis. Int. J. Oral Maxillofac. Implants 2018, 33, 824-830. [CrossRef] [PubMed]

28. Di Stefano, D.A.; Arosio, P.; Perrotti, V.; Iezzi, G.; Scarano, A.; Piattelli, A. Correlation between Implant Geometry, Bone Density, and the Insertion Torque/Depth Integral: A Study on Bovine Ribs. Dent. J. (Basel) 2019, 7, 25. [CrossRef]

29. Almutairi, A.S.; Walid, M.A.; Alkhodary, M.A. The effect of osseodensification and different thread designs on the dental implant primary stability. F1000Res 2018, 7, 1898. [CrossRef]

30. Maglione, M.; Bevilacqua, L.; Dotto, F.; Costantinides, F.; Lorusso, F.; Scarano, A. Observational Study on the Preparation of the Implant Site with Piezosurgery vs. Drill: Comparison between the Two Methods in terms of Postoperative Pain, Surgical Times, and Operational Advantages. BioMed Res. Inter. 2019, 8483658, 1-6. [CrossRef]

31. Di Fiore, A.; Sivolella, S.; Stocco, E.; Favero, V.; Stellini, E. Experimental Analysis of Temperature Differences during Implant Site Preparation: Continuous Drilling Technique Versus Intermittent Drilling Technique. J. Oral Implantol. 2018, 44, 46-50. [CrossRef] [PubMed]

32. Bacci, C.; Lucchiari, N.; Frigo, A.C.; Stecco, C.; Zanette, G.; Dotto, V.; Sivolella, S. Temperatures generated during implant site preparation with conventional drilling versus single-drill method: An ex-vivo human mandible study. Minerva Stomatol. 2019, 68, 277-284. [CrossRef] [PubMed]

33. Scarano, A.; Piattelli, A.; Murmura, G.; Iezzi, G.; Assenza, B.; Mancino, C. Delayed expansion of the atrophic mandible by ultrasonic surgery: A clinical and histologic case series. Int. J. Oral Maxillofac. Implants 2015, 30, 144-149. [CrossRef]

34. Díaz-Castro, M.-C.; Falcao, A.; López-Jarana, P.; Falcao, C.; Ríos-Santos, J.-V.; Fernández-Palacín, A.; Herrero-Climent, M. Repeatability of the resonance frequency analysis values in implants with a new technology. Med. Oral Patol. Oral Cir. Bucal 2019, 24, e636-e642. [CrossRef]

35. López-Jarana, P.; Díaz-Castro, C.M.; Falcão, A.; Falcão, C.; Ríos-Santos, J.V.; Herrero-Climent, M. Thickness of the buccal bone wall and root angulation in the maxilla and mandible: An approach to cone beam computed tomography. BMC Oral Health 2018, 18, 194. [CrossRef]

36. Andrés-García, R.; Vives, N.G.; Climent, F.H.; Palacín, A.F.; Santos, V.R.; Climent, M.H.; Bullón, P. In vitro evaluation of the influence of the cortical bone on the primary stability of two implant systems. Med. Oral Patol. Oral Cir. Bucal 2009, 14, E93-E97.

37. Herrero-Climent, M.; Albertini, M.; Rios-Santos, J.-V.; Lázaro-Calvo, P.; Fernández-Palacín, A.; Bullon, P. Resonance frequency analysis-reliability in third generation instruments: Osstell mentor@. Med. Oral Patol. Oral Cir. Bucal 2012, 17, e801-e806. [CrossRef]

38. Ríos-Santos, J.V.; Menjívar-Galán, A.M.; Herrero-Climent, M.; Ríos-Carrasco, B.; Fernández-Palacín, A.; Perez, R.A.; Gil, F.J. Unravelling the effect of macro and microscopic design of dental implants on osseointegration: A randomised clinical study in minipigs. J. Mater. Sci. Mater. Med. 2018, $29,99$. [CrossRef]

39. Lahens, B.; Lopez, C.D.; Neiva, R.F.; Bowers, M.M.; Jimbo, R.; Bonfante, E.A.; Morcos, J.; Witek, L.; Tovar, N.; Coelho, P.G. The effect of osseodensification drilling for endosteal implants with different surface treatments: A study in sheep. J. Biomed. Mater. Res. Part B Appl. Biomater. 2019, 107, 615-623. [CrossRef] 
40. Açil, Y.; Sievers, J.; Gülses, A.; Ayna, M.; Wiltfang, J.; Terheyden, H. Correlation between resonance frequency, insertion torque and bone-implant contact in self-cutting threaded implants. Odontology 2017, 105, 347-353. [CrossRef]

41. O'Sullivan, D.; Sennerby, L.; Meredith, N. Measurements comparing the initial stability of five designs of dental implants: A human cadaver study. Clin. Implant Dent. Relat. Res. 2000, 2, 85-92. [CrossRef] [PubMed]

42. Trisi, P.; Berardini, M.; Falco, A.; Podaliri Vulpiani, M. New Osseodensification Implant Site Preparation Method to Increase Bone Density in Low-Density Bone: In Vivo Evaluation in Sheep. Implant Dent. 2016, 25, 24-31. [CrossRef] [PubMed]

43. Chávarri-Prado, D.; Brizuela-Velasco, A.; Diéguez-Pereira, M.; Pérez-Pevida, E.; Jiménez-Garrudo, A.; Viteri-Agustín, I.; Estrada-Martínez, A.; Montalbán-Vadillo, O. Influence of cortical bone and implant design in the primary stability of dental implants measured by two different devices of resonance frequency analysis: An in vitro study. J. Clin. Exp. Dent. 2020, 12, e242-e248. [CrossRef] [PubMed]

44. Comuzzi, L.; Tumedei, M.; Pontes, A.E.; Piattelli, A.; Iezzi, G. Primary Stability of Dental Implants in Low-Density (10 and 20 pcf) Polyurethane Foam Blocks: Conical vs Cylindrical Implants. Int. J. Environ. Res. Public Health 2020, 17, 2617. [CrossRef] [PubMed]

(C) 2020 by the authors. Licensee MDPI, Basel, Switzerland. This article is an open access article distributed under the terms and conditions of the Creative Commons Attribution (CC BY) license (http://creativecommons.org/licenses/by/4.0/). 